\title{
Transitioning to online learning in higher education: Influence of Awareness of COVID-19 and Self-Efficacy on Perceived Net Benefits and Intention
}

\author{
Krunal K. Punjani ${ }^{1}\left[\right.$ ' Kala Mahadevan ${ }^{1}[$
}

Received: 30 January 2021 / Accepted: 11 July 2021 / Published online: 2 August 2021

(c) The Author(s), under exclusive licence to Springer Science+Business Media, LLC, part of Springer Nature 2021

\begin{abstract}
The COVID-19 pandemic has disrupted existing educational systems worldwide. Due to lockdowns in several countries, the educational institutions have been directed by governments to move towards online learning. The challenge for educational institutions and faculty members is to assess the influence of various factors that would enable adoption of online learning by students in higher education. This study investigates the influence of awareness of COVID-19 (AOC19), computer \& internet self-efficacy (CISE), and online communication self-efficacy (OCSE) on perceived net benefits (NB) of the students and their intention towards the online learning (INT). The study further analyzes the mediating role of students' attitude towards online learning (ATOL). Data of 1023 students of higher education across multiple universities in India were collected and analyzed using structural equation modelling through AMOS 24 and mediation analysis through 'PROCESS' macro for SPSS. The findings revealed that, AOC19 positively influenced students' NB and INT; CISE had a significant inverse relationship with NB, and partially significant positive relationship with INT; OCSE was observed to be a significant predictor of NB with positive direct relationship; ATOL had a significant full mediation among CISE and NB, and acted as significant partial mediator between CISE and INT, AOC19 and NB, AO19 and INT, OCSE and NB, and OCSE and INT. This paper would be useful for the faculty members, institutions and education technology companies in the higher education domain by enabling an understanding of the attitude, perception and intention of the students towards online learning during the COVID-19 scenario.
\end{abstract}

Keywords Online Learning · Higher Education - Perceived net benefits · Attitude · Intention · COVID-19

Krunal K. Punjani

profkrunal@gmail.com

Extended author information available on the last page of the article 


\section{Introduction}

Technology has enabled the adoption of electronic learning and online learning systems increasingly over the past couple of decades as an important component of knowledge delivery in several universities across the world (Lin et al., 2013). Richardson and Swan (2003) defined online learning as "any class that offers its entire curriculum in the online course delivery mode, thereby allowing students to participate regardless of geographic location, independent of time and place". The outbreak of the novel coronavirus pandemic (COVID-19) as a public health phenomenon has caused drastic changes in the way education is being imparted across the world. The pandemic resulted in a world-wide lockdown in many countries and to ensure the social distancing, all educational institutions in India stopped classroom teaching. Nonetheless, to continue the education process, the apex education regulatory bodies in India - the University Grants Commission (UGC) and the All-India Council for Technical Education (AICTE) advised colleges and universities to move towards online learning modes of education (Sreehari, 2020). Both faculty members and students are facing significant challenges in adapting to the online learning environment. (Adarkwah, 2020; Almaiah et al., 2020). Many countries are contemplating the continuance of the online learning mode in the near future in order to maintain social distancing (Mo et al., 2021). In light of the possible continuance of online learning mode, it is important for educational institutions to investigate the factors that would influence the adoption of online learning by students with a positive mindset.

Researchers have examined the online learning through various lenses such as identification of key factors, technology adoption, assessment of issues with respect to online learning systems, and student and faculty satisfaction with online learning (Buchanan et al., 2013; Caliskan et al., 2017; Liu et al., 2010; Rajabalee \& Santally, 2020). However, an assessment of the impact that factors such as the awareness of the COVID-19 pandemic, computer \& internet self-efficacy as well as online communication self-efficacy on the perceived net benefits that would accrue to students, intention of the students to adopt online learning systems and the mediating role of attitude has not received due attention. Given the current pandemic situation, a study of the factors which would impact the adoption of online learning by students in higher education has a practical orientation from the perspective of students, faculty members, institutions and education technology companies.

The following research questions emerged from a review of the extant literature and were sought to be addressed through this study.

1. Does an awareness of the COVID-19 pandemic impact students' perception of net benefits from online learning and their intention to adopt online learning?

2. Do students' Computer \& Internet Self-efficacy and Online Communication Selfefficacy influence their perception of net benefits from online learning and their intention to adopt online learning? 
3. Does Attitude play a mediating role in the relationships between the awareness of the COVID-19 pandemic, the self-efficacies of the students on one hand and their perception of net benefits and intention to adopt online learning on the other?

This study makes four significant contributions to the academic body of knowledge in the field of online learning. The first contribution is in the form of exploring how the exogenous construct of 'Awareness of COVID-19' (AOC19) can have an impact on the 'Perceived Net Benefits' (NB) accruing from adopting an online learning format by students and also influence their 'Intention towards online learning' (INT). The second contribution is assessment of the impact of additional exogenous constructs in the form of two types of self-efficacy viz., 'Computer \& internet self-efficacy' (CISE) and 'Online communication self-efficacy' (OCSE) on NB as well as the students' INT in higher education. The third contribution pertains to the perusal of 'Attitude towards online learning' (ATOL) as a mediating variable between the three exogenous constructs mentioned above and the endogenous constructs of NB and INT. The construct of NB has typically been examined from a perspective of benefits that accrue to the various stakeholders in an organization from the adoption of a technology-based system (Bhuasiri et al., 2012; DeLone \& McLean, 2003; Hassanzadeh et al., 2012; Zhang \& Thompson, 2019). Our fourth contribution by way of this study is the examination of the construct NB in an online learning in a higher education environment which in our view has been examined only in relatively fewer studies (Salam \& Farooq, 2020).

This paper is further structured as follows. Section 2 outlines the theoretical framework used as the basis for the conceptualization of the study, followed by review of relevant literature of the key constructs and hypotheses proposed in this study in the Sect. 3. Further, Sect. 4 addresses the research methodology adopted for the study while Sect. 5 details the statistical analysis and results. Subsequently, discussion based on the results is provided in the Sect. 6 while Sect. 7 outlines the theoretical, practical and social implications of the study. The conclusions, limitations and the future research directions have been detailed in Sect. 8.

\section{Literature review}

\subsection{Online learning}

Research on online learning in pre-COVID-19 times has indicated mixed results on the efficacy of online learning systems when assessed through various contexts. Means et al. (2013) posit that the performance of e-learners is marginally better than those in traditional face to face learning environments. Mosquera (2017) reported that the virtual learning environment was found to be productive and useful by teachers. Mathew et al. (2019) reported that faculty members faced several impediments such as students being non-responsive during online classes, inability of the teachers to supervise the student learning process and difficulties in teaching online for longer periods of time. 
Previous research in the domain of online learning has investigated this field from several perspectives. Volery and Lord (2000) investigated the key success factors required for online education. Abdullah et al. (2016) explored the influence of selfefficacy, subjective norms, enjoyment, computer anxiety and experience on students' perceived ease of use and perceived usefulness. Hung et al. (2010) developed a scale to assess learner readiness which outlined five key dimensions to assess learner readiness in online learning systems - self-directed learning, motivation for learning, online communication self-efficacy, computer/ internet self-efficacy and learner control.

Research on online learning perspectives during the COVID-19 pandemic has focused on the effectiveness of the shift to online learning and teaching systems and the issue of student assessment thereof (Al-Hattami, 2020). Researchers have also examined the critical success factors for online learning during the COVID-19 pandemic (Alqahtani \& Rajkhan, 2020), the difficulties in online learning systems (Chang \& Fang, 2020) and learners' acceptance of the migration to online learning (Mukhtar et al., 2020).

The domain of higher education is on a transitionary mode and is currently experiencing a period of great change. Given the current situation wherein the shift to online learning systems has been more or less mandated by the ongoing pandemic, an awareness of the dangers of having face to face classes (Munir et al., 2021) and an understanding of the need to move towards an online format of education is imperative. The successful implementation of online learning can translate into benefits for the students, only if they have a favorable attitude towards the online learning format (Salam \& Farooq, 2020; Shaft et al., 2004). In addition, their skills pertaining to computer $\&$ internet efficacy and online communication efficacy would act as enablers in the entire process (Hung et al., 2010).

\subsection{Theoretical framework}

This study bases itself on the theoretical foundation offered by the Stimulus-Organism-Response (SOR) model proposed by Mehrabian and Russell (1974). The SOR model proffers that multiple environmental factors can act as stimulus (S) which can influence an individual's external state specified in the model as organism (O) and this can thereafter drive the individual's behavioral response (R). This model therefore comprises of three components - "stimulus/stimuli" - these are considered external to the person which can evoke affective responses reflected through emotions and feelings (Batra \& Ray, 1986), “organism" - which encompasses the inner state of the individual's thinking, feelings and perceptions and these affective and cognitive states act as a mediator between the stimulus and the "response" which is essentially the final outcome of the individual's behavior (Moon et al., 2017). Significant research using the SOR model has been carried out in exploring online user behaviors in online shopping and electronic commerce transactions (Kim \& Lennon, 2012; Moon et al., 2017). However, very few studies (Zhai et al., 2020) have used this model to examine user behavior in online learning settings. 
Previous studies have classified stimuli as being of two types - social and psychological stimuli that originate from the external environment in which an individual exists and object stimuli that comprise of product characteristics and other object attributes (Arora, 1982). In our study, AOC19 is considered to be one such external stimuli, which is of a social and psychological nature. The theoretical foundation is further strengthened with the addition of the Social Cognitive Theory (Bandura, 1977, 1982) which offers a conceptual framework for understanding how self-efficacy of an individual has a significant effect on cognitive and affective processes. Thus, this study uses two measures of self-efficacy - CISE and OCSE as additional environmental stimuli which can trigger a cognitive and affective response in an individual.

The SOR model outlines three emotional states - pleasure, arousal and dominance as represented by "organism" (Mehrabian \& Russell, 1974). Prior research on this subject has also extended the internal states of the organism to include other variables such as cognition, value, emotion and affect (Fiore \& Kim, 2007; Lee et al., 2011). Previous research studies have operationalized attitude as the "organism" in the SOR model in multiple contexts (Chen \& Huang, 2012; Kaur et al., 2017; Lee et al., 2011; Moon et al., 2018; Romero et al., 2021; Suparno, 2020; Vergura et al., 2020). Through this study, we seek to make a significant contribution to the existing body of knowledge on the SOR model by operationalizing attitude as an emotional state represented by "organism" in the model and seeking to assess the impact of external stimuli on the attitude of a student towards online learning.

NB has been proposed as a dependent variable in several studies. Hassan et al (2015) examined the success of information systems in higher education in an e-government context. The study concluded that the usage of the e-government information systems leads to net benefits which indicate the success of the information system. Lwoga (2013) researched the suitability of information systems (IS) success model with respect to the adoption of library 2.0 technologies among undergraduate students in Africa by positing net benefits to the students and users as the final outcome variable. Xinli (2015) examined the impact of using an Electronic Monitoring System on reducing corruption in China. The study concluded that application of such systems has a positive effect on reduction in corruption levels which was construed as a net benefit for organizations and the society at large. Thus, NB is construed as a "response" in the SOR framework used in the study.

Furthermore, the conceptual foundation offered by the SOR model and the Social Cognitive Theory is sought to be augmented by integrating the Theory of Reasoned Action (Ajzen \& Fishbein, 1975, 1977) and the Theory of Planned Behavior (Ajzen, 1985). The Theory of Reasoned Action (TRA) posits that an individual's behavior towards an object is formed by the intention to perform that particular behavior. According to this theory, an individual's attitudes are determined by the beliefs held by the individual about the consequences of his/ her behavior and also suggests that external stimuli influence attitudes by suitably modifying the structure of the individual's beliefs (Ajzen, 1985). The TRA framework has been extensively used to predict consumer intentions and behavior (Casselman \& Damhorst, 1991; Gentry \& Calantone, 2002). This study uses the TRA framework to assess the impact of the stimuli on an individual's attitude towards online learning, the net benefits that an 
individual perceives from the online learning system and finally, the intention of the individual towards the online learning system. Thus, INT is also envisaged as the "response" in the SOR framework used in the study.

Ajzen (1985) extended the TRA as Theory of Planned Behavior (TPB) by adding one more predictor to the existing TRA model in the form of Perceived Behavioral Control. This predictor accounts for those instances wherein an individual has the intention of carrying out a particular behavior but is restrained from doing so due to lack of confidence or control over such behavior. This construct was referred to by information systems literature as the concept of "self-efficacy", which has been reflected by the use of the two self-efficacy related constructs of CISE and OCSE in this study.

The Information Systems (IS) model developed by DeLone and McLean (1992, 2003) envisaged the outcomes of an information system as a manifestation of the overall impact that the information system has on an organization. This study proposes to extend DeLone and McLean's (2003) updated IS model to the online learning environment by envisaging the contributions of an online learning system as its NB.

The use of multiple theoretical frameworks to support constructs used in research has been employed in several studies across various research domains (Alzahrani \& Seth, 2021; Dalvi-Esfahani et al., 2020; Farooq et al., 2019; Hausman \& Siekpe, 2009; Hung et al., 2010; Liao et al., 2017; Lim \& Tai, 2014; Udo et al., 2010; Yusuf et al., 2018; Zhou, 2016; Zahid \& Haji Din, 2019).

\section{Constructs and hypotheses}

\subsection{Awareness of COVID-19}

The COVID-19 pandemic has emerged as a once-in-a-generation black swan event (Krishnamurthy, 2020; Taleb, 2007). In order to maintain social distancing, educational institutions were directed by governments to transition towards online learning systems. Migrating to an online learning format could offer a more convenient method of continuing the education process in the prevailing pandemic situation (Al-Hattami, 2020). This study has considered "Awareness of COVID-19" (AOC19) as a relevant "stimulus" as the survey for this research was conducted in the early phase of the pandemic wherein people at large were just getting an awareness of the dangers that the pandemic posed. We represent the construct of AOC19 as "an awareness of the benefits of shifting towards an online learning platform and perceiving it as a convenient method of continuing education so as to possibly minimize the chances of contracting COVID-19".

Previous studies have focused on the difficulties and solutions thereof with respect to online learning (Chang and Fang, 2020), e-assessment of student performance during online learning in COVID-19 pandemic situation (Al-Hattami, 2020), salient factors for online learning during COVID-19 pandemic and transitioning from face-to-face lectures to an online learning environment during the COVID-19 pandemic (Mpungose, 2020). However, there is a need to also understand, whether 
AOC19 leads to NB and INT and hence, considering AOC19 as a 'stimulus' in the SOR framework, we propose the following hypotheses:

H1: AOC19 has a significant impact on NB

H2: AOC19 has a significant impact on INT

\subsection{Self-Efficacy in online learning}

Self-efficacy is believed to be one of the key factors for successful online learning. It includes a learner's evaluation of his/her own ability to achieve a goal or the learner's self-belief to achieve that goal (Yokoyama, 2019). Several research studies have investigated various types of self-efficacy in an online learning system such as technology self-efficacy (Choi et al., 2007), computer self-efficacy (Kim \& Park, 2018; Lim et al., 2016), e-learning system self-efficacy (Jashapara \& Tai, 2006), academic self-efficacy (Lim et al., 2016), knowledge sharing self-efficacy (Tseng \& Kuo, 2010), internet self-efficacy (Chiu \& Tsai, 2014), communication-internet selfefficacy (Chu, 2010) and online learning self-efficacy (Hong et al., 2017).

Shen et al., (2013) investigated the various dimensions of self-efficacy through an exploratory factor analysis and the study identified five dimensions of self-efficacy with respect to online learning:

a. Self-efficacy to complete an online course

b. Self-efficacy to interact socially with classmates

c. Self-efficacy to handle tools in a course management system.

d. Self-efficacy to interact with instructors in an online course.

e. Self-efficacy to interact with classmates for academic purposes

An extensive review of the literature on self-efficacy in online learning systems indicated that there were two key self-efficacies that were required to successfully navigate an online learning system. These related to the handling of the technology/ computer/ tools used in online learning (Dimensions (a) and (c) as outlined by Shen et al., 2013) and the efficacies related to communicating online with other students and faculty members (Dimensions (b), (d), and (e) as outlined by Shen et al., 2013). Hence, CISE and OCSE were the constructs considered and this study has employed the scales suggested by Hung et al, (2010) for these constructs.

\subsubsection{Computer \& Internet Self-Efficacy}

There has been significant research carried out on Self-Efficacy which has been construed to arise from the acquisition of cognitive, social and linguistic skills over a period of time through experience (Bandura, 1982). CISE is the belief of an individual about his/ her ability to use a computer and the internet (Compeau \& Higgins, 1995). The idea of self-efficacy also stems from the social cognitive theory which outlines how beliefs about self-efficacy can regulate functioning of individuals (Bandura, 1977). Compeau and Higgins (1995) developed a scale for measuring 
computer self-efficacy and posited that computer self-efficacy had a significant influence on emotional responses and actual use of computer-based technologies. Eastin and LaRose (2000) examined the concept of internet self-efficacy and stipulated that it is the ability of an individual to harness internet skills in an online learning environment. Based on the SOR framework and the social cognitive theory, we proffer the following hypotheses:

H3: CISE has a significant impact on NB.

H4: CISE has a significant impact on INT.

\subsubsection{Online Communication Self-Efficacy}

Another key self-efficacy is that of an individual being able to communicate effectively online. Interaction and communication provide a critical link between teachers and students in online learning environments (McVay, 2000) and these communications may serve to enrich the overall perceived benefits from online learning. Roper (2007) stipulated that the students should aim at using online discussions to learn better as these typically provide opportunities for in-depth delving into the subject. Online discussions also act as a facilitating tool for better engagement between teachers and students. Hung et al. (2010) have developed and validated a scale for measurement of OCSE and observed that students with better OCSE also felt more comfortable in expressing themselves in the written form. Considering OCSE as a 'stimulus' in the SOR framework, the following hypotheses are proposed:

H5: OCSE has a significant impact on NB.

H6: OCSE has a significant impact on INT.

\subsection{Perceived Net Benefits}

The concept of NB refers to the degree to which an information system benefits an individual, group or a firm (Alzahrani et al., 2017). Most studies examining this concept examine the contributions of an information system as its net benefits for the various stakeholders in an organization (Salam \& Farooq, 2020). Yet other researchers have opined that the perception of net benefits may vary from user to user and from system to system (Marnewick, 2016). The Information Systems (IS) model developed by DeLone and McLean (1992, 2003) envisaged the outcomes of an information system as a manifestation of the overall impact that the information system has on an organization. DeLone and McLean (2003) in the IS model have postulated that the ultimate parameter of the success of any system is the net benefits that the system generates. While encouraging positive attitudes or mindful usage of the system may be an important concern, the goal of any system should be the net benefits that the system provides. Hence the IS Model posits net benefits as the final dependent variable. Net benefits in the IS model are also influenced by user satisfaction. As satisfaction in the IS model includes items that measure attitude, it has been theorized in the IS model that attitude has a direct effect on net benefits (Jewer 
et al., 2017). This study proposes to extend DeLone and McLean's (2003) updated IS model to the online learning environment by envisaging the contributions of an online learning system as its NB. Previous researchers (Anaya, 2013; Kurkalova \& Carter, 2017) have opined that the construct of NB has not been explored fully to date and more so in the arena of online education. This study attempts to answer this call for research by conceptualizing NB as an outcome of online learning systems in the higher education domain.

\subsection{Intention towards Online Learning}

Online learning is gaining prominence in higher education (Abdel-Wahab, 2008) and due to COVID-19, higher educational institutions are required to quickly adapt to online learning environments. Previously, many researchers (de Souza Rodrigues et al., 2021; Sidik \& Syafar, 2020; Xu \& Wang, 2017) have studied students' intention in the online learning environment and considered it to be a substantial outcome. This study focuses on assessing the association between the exogenous constructs of AOC19, CISE and OCSE on the students' intention towards online learning as a way of education.

\subsection{Attitude towards Online Learning}

A key component of the individual's intention to adopt an online learning system is the attitude that is formed by the individual based on the stimuli that he/she has been exposed to. An understanding of an individual's attitude can enable the prediction of the individual's overall response to a particular object. and the link between attitude and behavior has been well established in research literature through the Theory of Reasoned Action (Ajzen \& Fishbein, 1977). The concept of attitude has typically been examined in research with a view to understanding its mediating relationship between various exogenous constructs and behavioral intentions such as purchase/ repurchase/ revisit intentions (Evans \& Bang, 2019; Hausman \& Siekpe, 2009) or intention to adopt a specific technology (Irani et al., 2013; Wahid, 2007).

Researchers have also examined the role of attitude as a mediating variable in the adoption of online learning systems (Alenezi \& Karim, 2010; Ndubisi, 2004; Yasin et al., 2020). Markova and Jones (2011) examined benefits satisfaction as an attitude formed through the beliefs about benefits and the perceived value of these benefits in an organizational environment. However, only a few research studies have focused on the association between attitude and NB. Koh et al., (2010) evaluated a model for mandatory usage of software technologies wherein attitude mediated the relationship between several exogenous constructs (information quality, performance expectancy, social influence and information satisfaction) and usage and overall satisfaction which further led to net benefits. Elmorshidy (2018) examined the impact of knowledge management systems on innovation and posited that attitude as a mediating variable between exogenous constructs and intention leading to usage and thereby and net benefits. Almalki et al., (2013) developed a conceptual framework to evaluate the success of e-Government portals and proposed that attitude would 
mediate the relationship between several exogenous constructs (Information quality, System quality, Service quality, Perceived risk, Perceived ease of use, Perceived Usefulness) and Behavioral intention to use the portal which would further influence the usage and perceived net benefits from the portals.

This paper seeks to contribute to academic literature by positing ATOL as a mediating variable in the relationship between the exogenous constructs of AOC19, CISE and OCSE and the endogenous constructs of NB and INT. Based on the above, the following hypotheses are proffered:

H7: ATOL mediates the association between AOC19 and NB.

H8: ATOL mediates the association between CISE and NB.

H9: ATOL mediates the association between OCSE and NB.

H10: ATOL mediates the association between AOC19 and INT.

H11: ATOL mediates the association between CISE and INT.

H12: ATOL mediates the association between OCSE and INT.

Based on the above discussion and hypotheses mentioned, this study proposes the following conceptual model: Fig. 1

\section{Research methodology}

\subsection{Construct and measurement development}

The proposed model for the study comprised of three exogenous constructs - AOC19, CISE and OCSE, one mediating construct - ATOL and two endogenous constructs - NB and INT. The measures used have been well established in

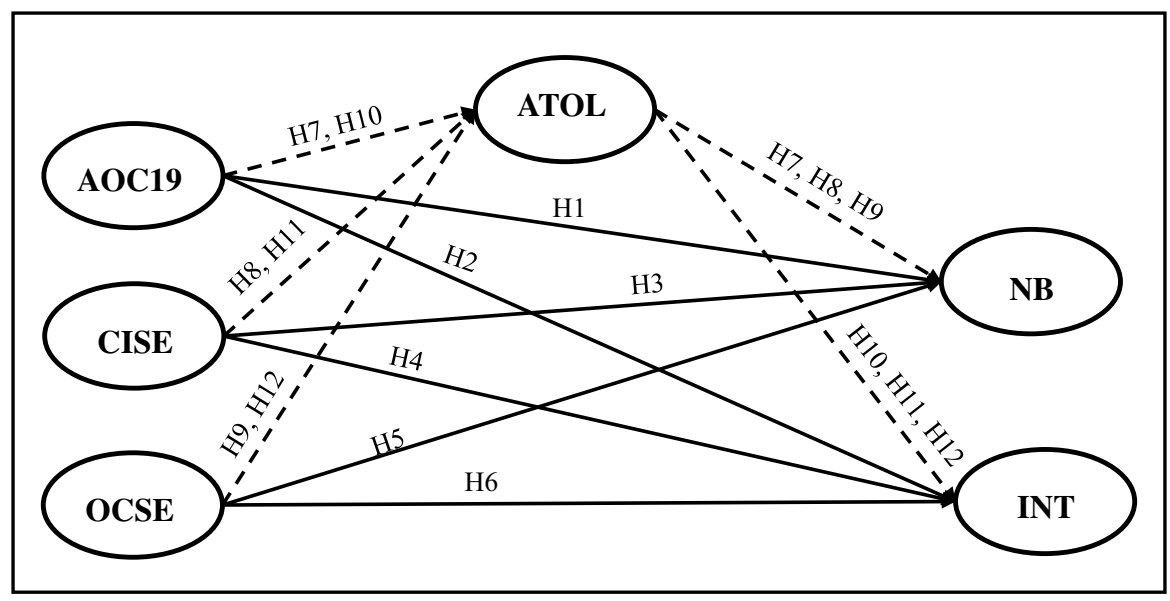

Fig. 1 Proposed Conceptual Model. Legend: AOC19: Awareness of COVID-19, CISE: Computer/ Internet Self Efficacy, OCSE: Online Communication Self Efficacy, ATOL: Attitude towards Online Learning, NB: Perceived Net Benefits, INT: Intention towards online learning 
prior research literature and care was taken to ensure that only previously validated measures were selected and these were suitably adapted to the online learning context to further enhance their validity. In order to measure AOC19, four items were adapted from a study investigating the effectiveness of the shift to online teaching and learning during the COVID-19 pandemic (Al-Hattami, 2020). CISE and OCSE were measured using three items each which were adapted from Hung et al. (2010). ATOL was measured using four items from Shaft et al. (2004), while NB was measured using five items from Salam and Farooq (2020). To measure the INT, three items were adapted from Ji et al. (2019); Xu and Wang (2017). A total of 22 items were used to measure the six constructs used in this study. All the items were measured on a five-point Likert Scale which measured the agreement/ disagreement of the respondents from "Strongly Disagree" to "Strongly Agree".

Table 1 synopsizes the items used for the measurement of each of the constructs used in the study along with the sources for the same.

\subsection{Sampling and data collection}

Sampling is a technique used in research in order to select a representative set of individuals from within a population so as to estimate the characteristics of the population. This study used non-probability based convenience sampling method by reaching out to faculty members who would have ready access to the students of higher education.

Data collection for the study was carried out by sending the questionnaire by email to 214 faculty members across several universities in India. As educational institutions were operating in online mode, it was deemed difficult to contact students of higher education directly. Hence, faculty members were chosen as the route to disseminate the questionnaire as they were in contact with the students through online learning classes. These faculty members were requested to forward the questionnaire to their respective students across multiple higher education courses. Higher education courses in India typically comprise "the education, which is obtained after completing 12 years of schooling or equivalent and is of the duration of at least nine months (full time) or after completing 10 years of schooling and is of the duration of at least 3 years" (Ministry of Human Resource Development, 2019). This mainly consists of graduation, post-graduation and other diploma or certification courses.

A total of 1023 responses were received through online survey and since there were no missing values in the collected data, all the responses were used for data analysis. The demographic profile of the respondents is outlined in Table 2.

\section{Statistical analysis and results}

\subsection{Sampling adequacy}

The Kaiser-Meyer-Olkin (KMO) test and Bartlett test of Sphericity were performed on the data to assess the suitability of the data for further factor analysis. The KMO 


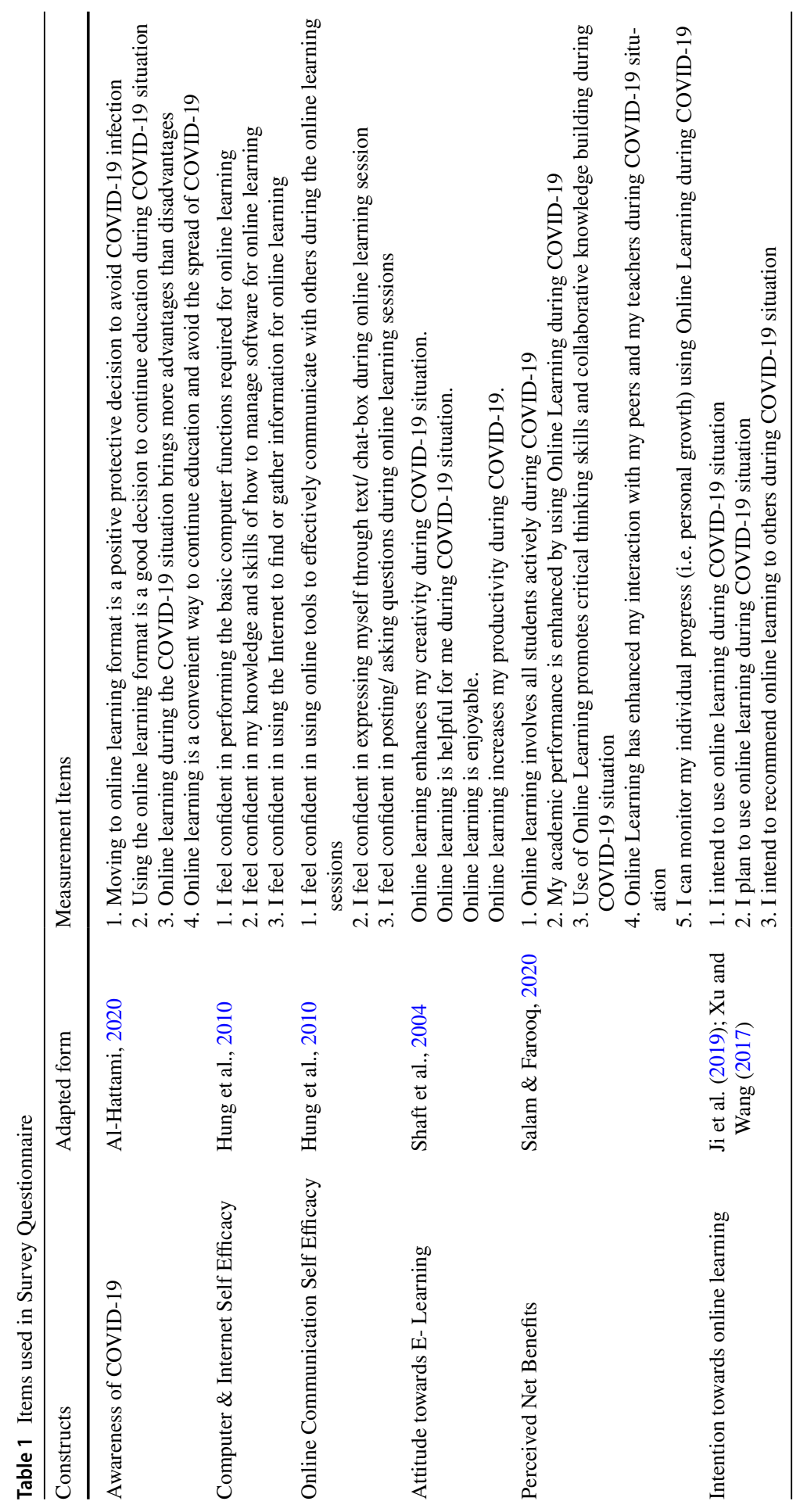


Table 2 Demographic Profile of Respondents

\begin{tabular}{llc}
\hline Categories & Frequency & $\%$ \\
\hline Gender & & \\
- Male & 283 & 27.66 \\
- Female & 740 & 72.34 \\
Age Group & & \\
- 16-20 years & 533 & 52.1 \\
- 21-25 years & 425 & 41.54 \\
- 26-30 years & 37 & 3.62 \\
- 31-35 years & 28 & 2.74 \\
Educational Course & & \\
- Junior college & 24 & 2.35 \\
- Graduation & 486 & 47.51 \\
- Post-Graduation & 298 & 29.13 \\
- Other & 215 & 21.02 \\
\hline
\end{tabular}

measure for our study was 0.957 , greater than the acceptable indicator of 0.5 , thus signifying that the sample was adequate to conduct a factor analysis. The Bartlett test was carried out to ensure that the variables were completely unrelated, thus concluding that a factor analysis would be appropriate for this set of data (Bartlett, 1950). Bartlett's test of sphericity indicated a significant value as outlined in Table 3.

\subsection{Construct reliability and validity}

The reliability and validity of the measurement model was sought to be assessed through Cronbach's $\alpha$ and a Confirmatory Factor Analysis (CFA) to examine the construct validity through factor loadings, Composite Reliability (CR) and Average Variance Extracted (AVE). The Cronbach Alpha values ranged from 0.772 to 0.879 , above the acceptable threshold of 0.70 for reliable scales (Hair et al., 2006; Nunnally, 1978). CR measures the shared variance among the observed variables of the respective constructs and has been used as an indicator of internal consistency (Fornell \& Larcker, 1981). The values for item wise factor loadings, Cronbach's $\alpha$, CR and AVE for each of the constructs used in the study are as presented in Table 4.

Convergent validity was assessed through an examination of the factor loadings, CR and AVE. Stevens (1996) has opined that sample sizes are important in understanding the significance of factor loadings which may vary with the size of

Table 3 KMO and Bartlett's Test

\begin{tabular}{lll}
\hline Kaiser-Meyer-Olkin Measure of Sampling Adequacy & & 0.957 \\
Bartlett's Test of Sphericity & Approx. Chi-Square & $12,529.381$ \\
& df & 231 \\
& Sig & 0.000 \\
\hline
\end{tabular}




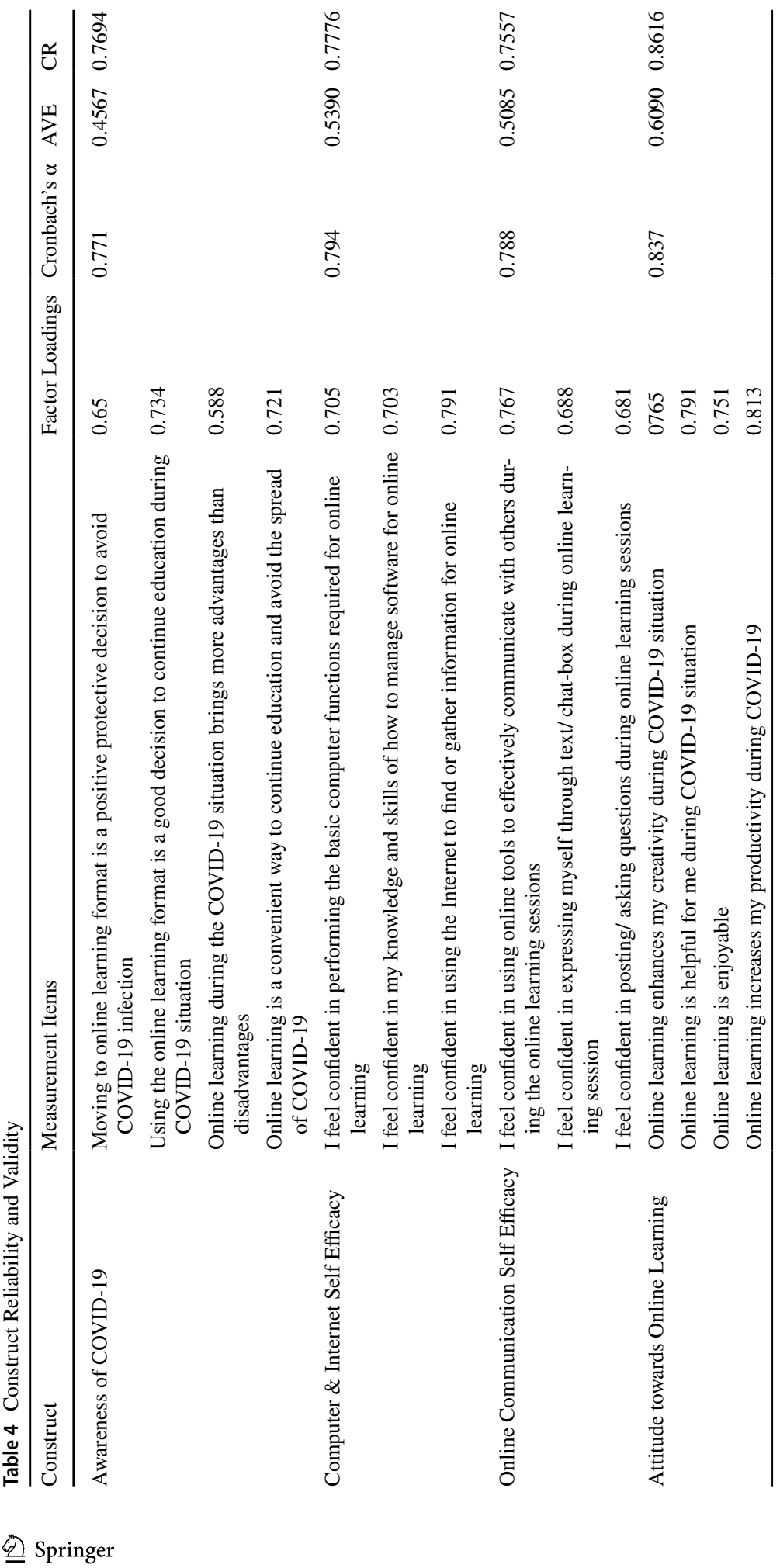




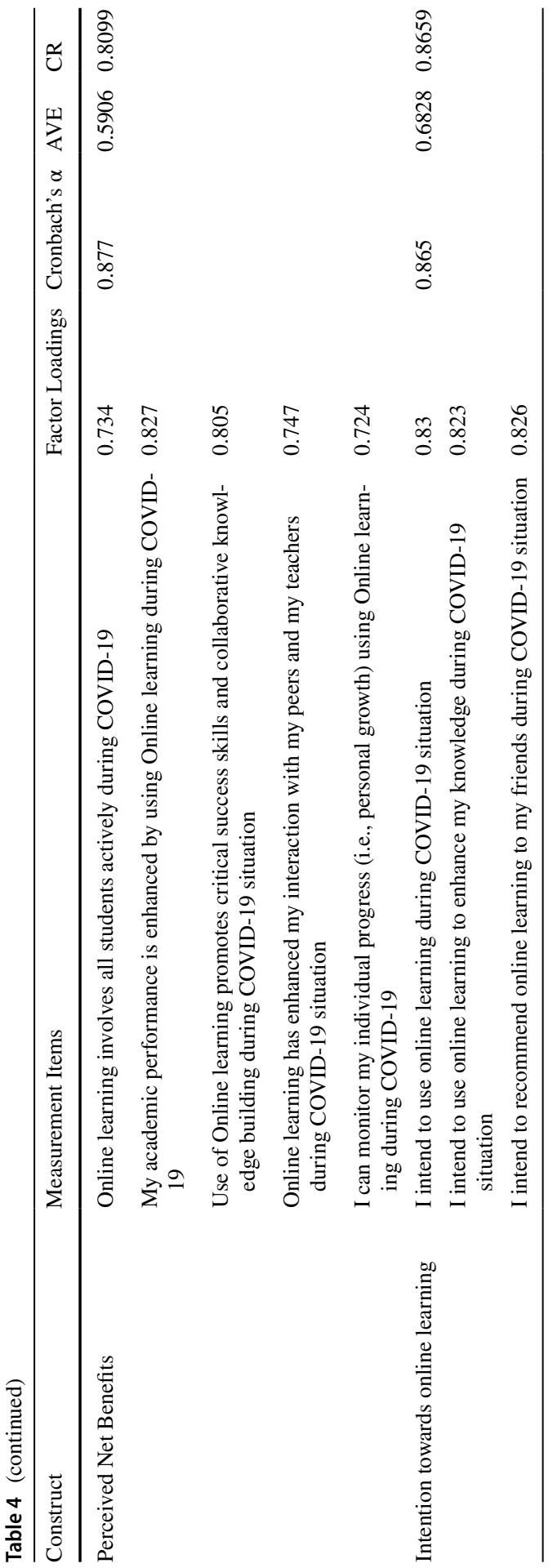




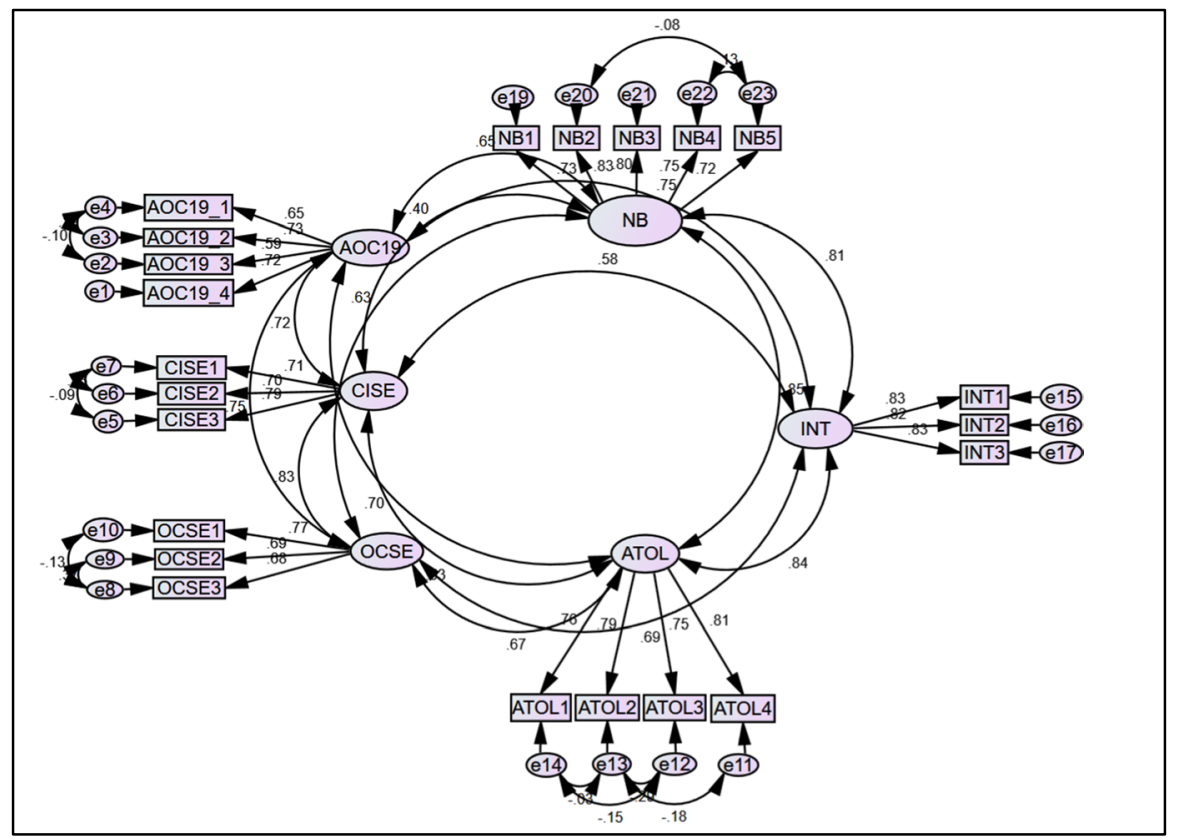

Fig. 2 Confirmatory Factor Analysis-Measurement Model. Legend: AOC19: Awareness of COVID-19, CISE: Computer \& Internet Self Efficacy, OCSE: Online Communication Self Efficacy, ATOL: Attitude towards Online Learning, NB: Perceived Net Benefits, INT: Intention towards online learning

the sample. Tabachnick et al. (2007) have cited that 0.32 is a good thumb rule for the minimum loading of an item. Hair et al. (2006) postulate that good convergent validity is demonstrated by item factor loadings greater than or equal to 0.5 . Other researchers like Field (2005), Ertz et al. (2016) have also considered factor loadings of greater than 0.4 to be significant. As can be seen from Table 4, all the 22 items have a factor loading of greater than 0.5 thus demonstrating good convergent validity. Additionally, the constructs in the proposed model demonstrate a CR ranging between 0.7557 and 0.8659 , well above the acceptable level of 0.7 (Fornell \& Larcker, 1981; Nunnally, 1978). Further, as suggested by Fornell and Larcker (1981) the AVE values of five constructs are greater than 0.5 , except one construct, the AVE of which is slightly less. Nevertheless, as stated by Fornell and Larcker (1981) "on the basis of pn (composite reliability) alone, the researcher may conclude that the convergent validity of the construct is adequate, even though more than $50 \%$ of the variance is due to error" (page no. 46), which was further supported by Lam (2012) and further by Safiih and Azreen (2016) as well.

Additionally, as the construct items of this study were adapted from the existing scales, CFA was conducted to assess the measurement model as shown in Fig. 2. This 


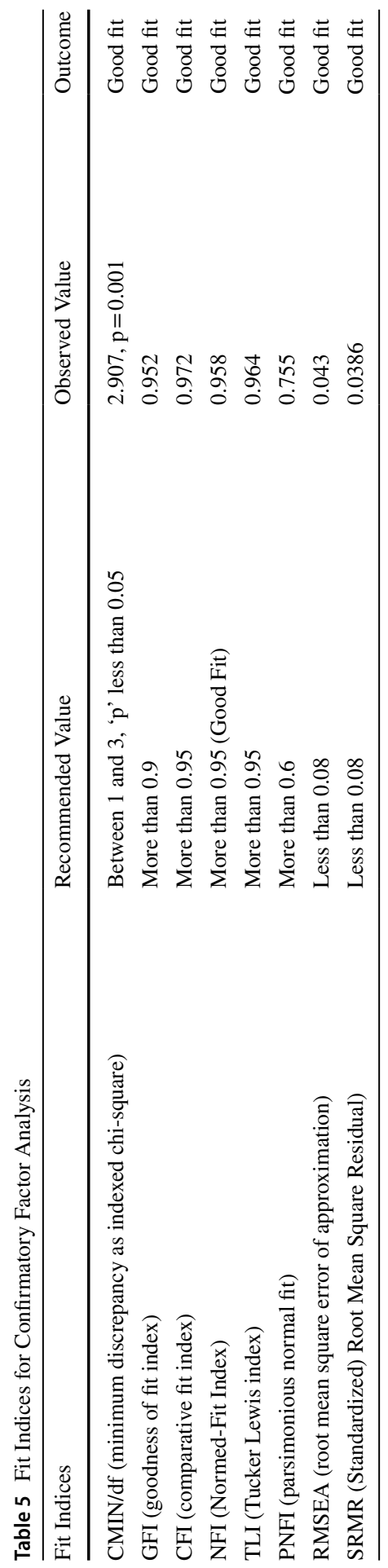




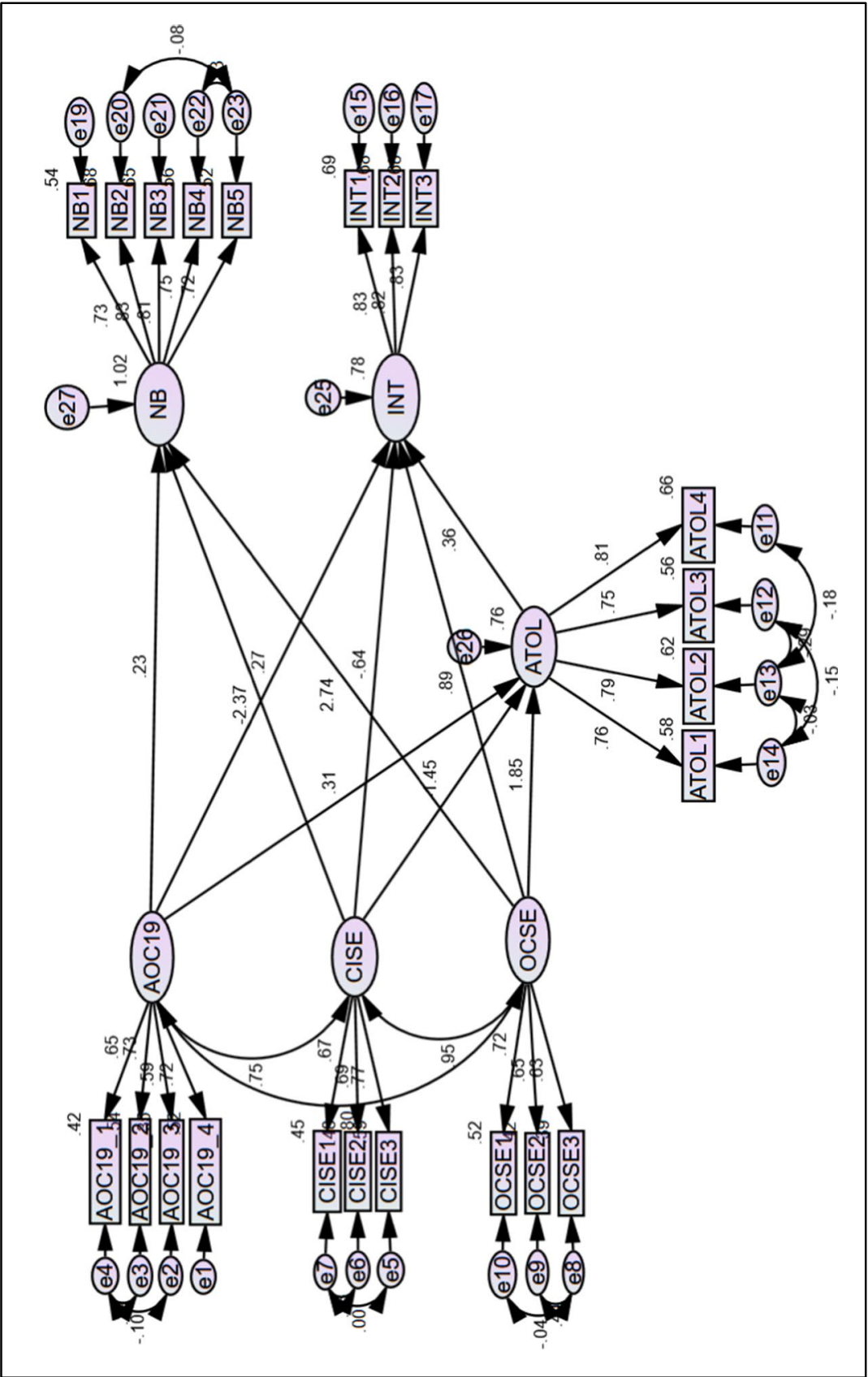

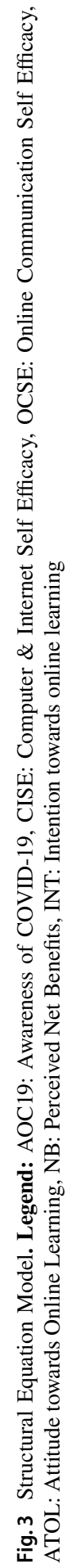


Table 6 Hypothesis Results - Construct Relationship

\begin{tabular}{llcll}
\hline $\begin{array}{l}\text { Hypothesis } \\
\text { Number }\end{array}$ & Construct Relationship & $\begin{array}{l}\text { Standardized } \\
\text { Regression Weight }\end{array}$ & Significance & Outcome \\
\hline $\mathrm{H} 1$ & AOC19 $\rightarrow$ NB & 0.177 & 0.004 & Significant \\
H2 & AOC19 $\rightarrow$ INT & 0.193 & $* * *$ & Significant \\
H3 & CISE $\rightarrow$ NB & -0.396 & $* * *$ & Significant \\
H4 & CISE $\rightarrow$ INT & 0.149 & 0.061 & Partially Significant \\
H5 & OCSE $\rightarrow$ NB & 0.369 & $* * *$ & Significant \\
H6 & OCSE $\rightarrow$ INT & -0.033 & 0.697 & Non-Significant \\
\hline
\end{tabular}

measurement model was evaluated through eight different fit indices, and as indicated in Table 5 and the value of all these indices were greater than the threshold limits suggested by Hair et al. (2006), Davey and Savla (2010) and Tabachnick et al. (2007).

In order to test the hypotheses, this study utilized Structural Equation Modelling (SEM) using AMOS 24 software. As suggested by Preacher and Hayes (2008), bootstrapping with 2000 samples was carried out to examine path coefficients and corresponding significance levels. As shown in Fig. 3 and Table 6, the first six proposed hypotheses were tested to check the direct relationships among the constructs. Further, by applying SEM, it was determined that of the six direct hypotheses proposed, four hypotheses were accepted with significant values of $\mathrm{p}<0.05(\mathrm{H} 1, \mathrm{H} 2$, H3 \& H5). This reveals that NB is significantly influenced by the three exogenous constructs of AOC19, CISE and OCSE. Moreover, it can be observed that standardized regression weights of CISE show negative values, which indicates an inverse relationship of CISE with NB. Additionally, INT was also found to be significantly influenced by AOC19 as $\mathrm{H} 2$ has been accepted. In case of $\mathrm{H} 4$ it can be noted that it is partially significant with $p$ value of 0.061 (considering $p<0.1$ ), whereas H6 was found to be non-significant. Findings of the H4 reflects CISE to be a partial predictor of the endogenous construct INT.

The six mediation hypotheses ( $\mathrm{H} 7$ to $\mathrm{H} 12)$ proposed in this study were tested using the Preacher and Hayes (2004) approach, where bootstrapping procedure is utilized to analyze the indirect effect of mediator, between the exogenous and endogenous constructs. Table 7 highlights estimate values of mediator's indirect effect, which were calculated using 'PROCESS' macro for SPSS, written by Andrew F. Hayes. The mediation analysis suggested that Attitude towards online learning fully mediated the relationship between Computer and Internet Self-Efficacy and Perceived Net Benefits (H8). In case of other five hypotheses H7 and H9 to H12, partial mediation was observed. Thus, it is evident that Attitude towards online learning was found to mediate the relationship of exogenous and endogenous constructs considered in this study. 


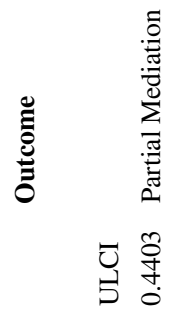
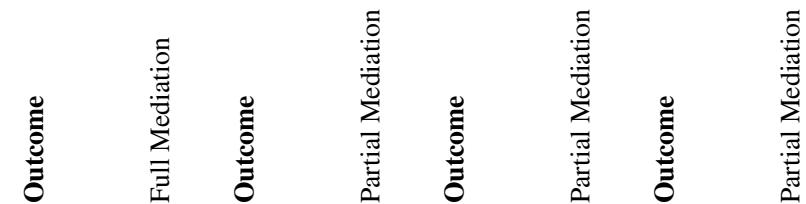

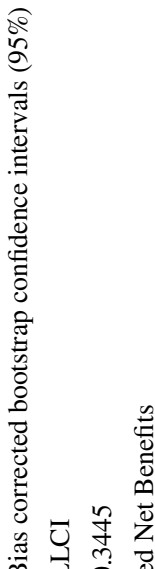

可高

$\stackrel{\vec{b}}{\stackrel{D}{\vec{J}}}$

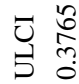

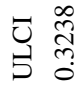

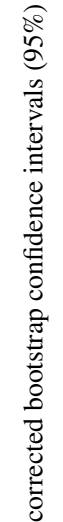

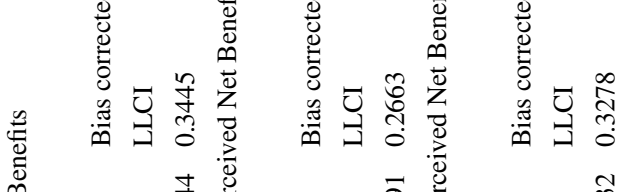

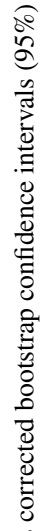

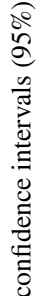

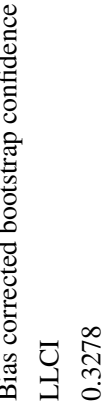

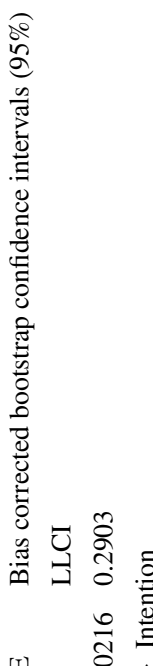

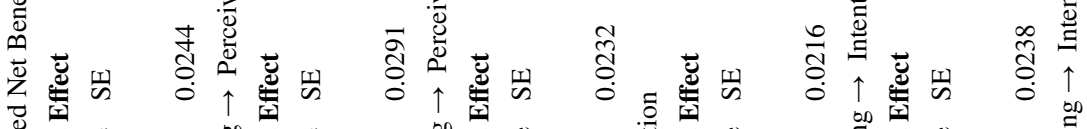

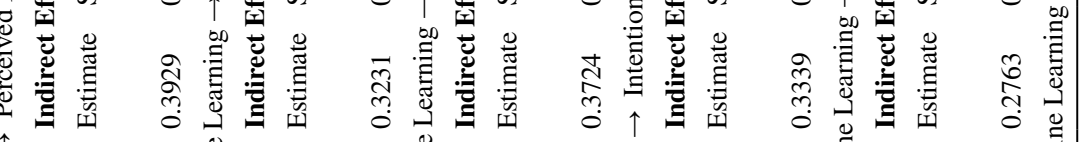

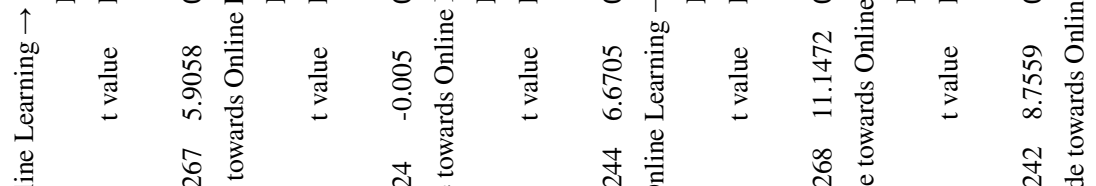

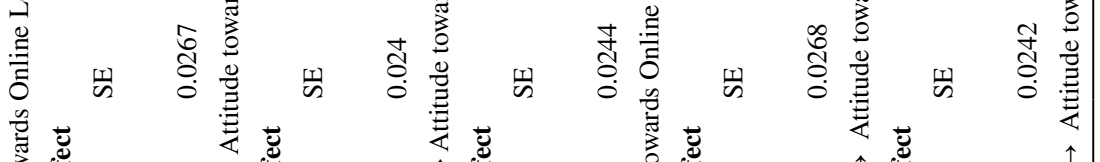

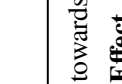

悹

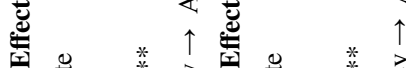

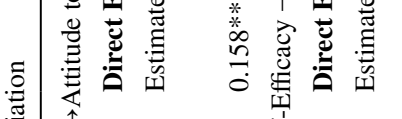

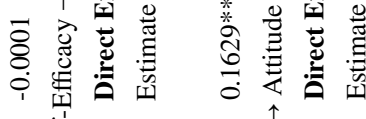

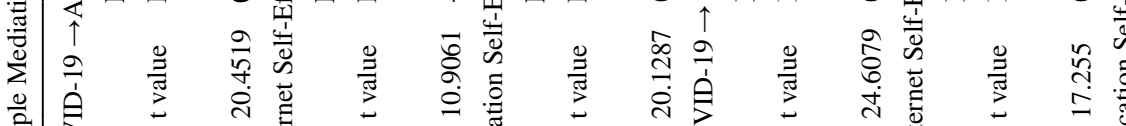

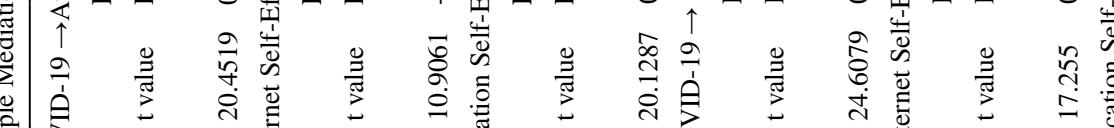

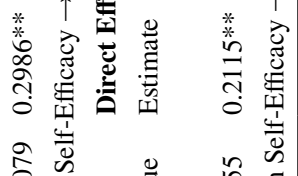

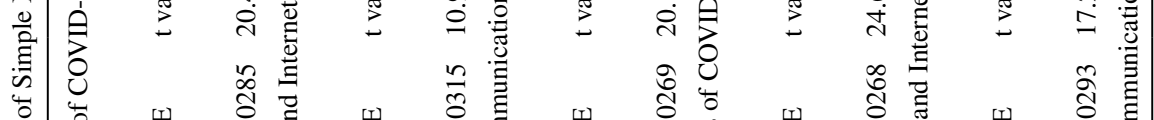

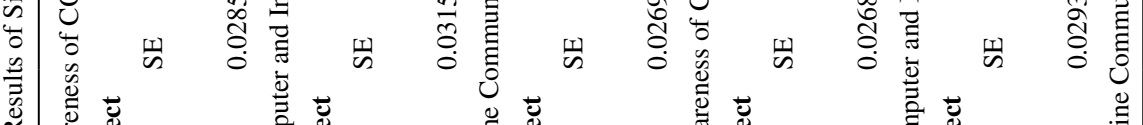

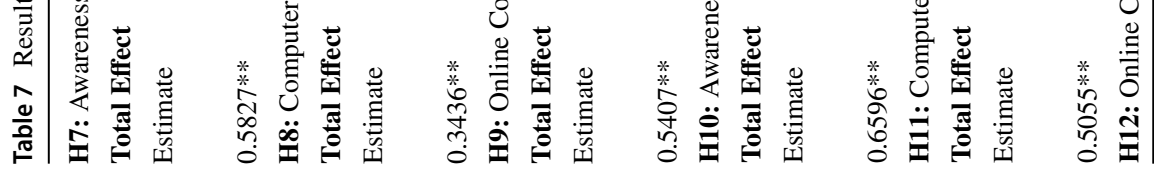




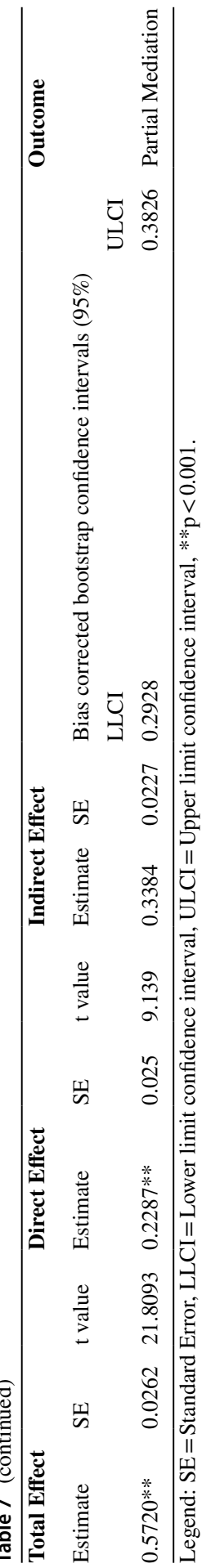




\section{Discussion}

Existing literature of online learning have focused on the online learning readiness (Hung et al, 2010), attitude towards computers instrument (Shaft et al, 2004), attitude towards computer-based learning (Hahne et al., 2005; Wenzel \& Gotfredsen, 1997), attitudes towards online cooperative learning (Korkmaz, 2012), attitude with respect to personnel and dispositional aspects, procedural characteristics, negative effects and internalization and habituation of use (Coelho Junior et al., 2019), student satisfaction (Liu \& Zhao, 2018; Salam \& Farooq, 2020). Whereas, this study has attempted to understand the direct effect of online learning during the COVID19 scenario, on the students' NB and INT (H1 to H6). Moreover, the study has also emphasized on determining how ATOL as a mediator influences NB and INT (H7 to $\mathrm{H} 12$ ), which is an under researched area in the online learning domain. The findings of this study are also useful to understand the contribution of CISE and OCSE on the students' perception of NB and INT during the COVID-19 pandemic.

The findings of the study disclosed that AOC19 has significant positive relationship with NB and INT. This shows that AOC19 has positively influenced the students in higher education to have a positive intention towards the online learning methods and approaches adopted by their respective colleges and universities. Additionally, these students also have a positive perception about the net benefits being derived from their online learning experience. These results support the findings of Al-Hattami (2020) which claimed online learning to be more convenient way to continue education during COVID-19 situation.

CISE was found to have a significant, but inverse relationship with NB. This suggests that higher education students having beliefs about their self-ability to use the computer and internet, do not necessarily drive the positive perception of net benefits of the online learning, but can inversely affect the same. This could be due to the rising expectations of the higher education students from online learning tools and methods, as their CISE increases, and if these expectations are not met, they tend to have negative perception about the net benefits. However, CISE's impact on INT was seen to be positive and partially significant, which was consistent with the findings of Alenezi et al. (2010), Albashrawi et al. (2020) and Fianu et al. (2020).

The study further ascertained OCSE as a significant and positive predictor of NB. This implies that higher education students with ability to effectively communicating online, stimulates the positive perception of net benefits towards online learning. This can be due to the students' ability to communicate effectively over the online platforms which may boost their confidence, subsequently resulting in positive perception towards NB. With respect to INT, though previously Sumuer (2018) found it to be significantly influenced by OCSE, this study revealed to have a non-significant direct relationship among these two constructs.

In the present study, ATOL was considered to be a mediator for the three exogenous constructs and their indirect relationship with NB and INT. ATOL was found to have a significant full mediation among the relationship of CISE and NB. This entails that mediation of ATOL changes the negative direct relationship into a positive indirect relationship with students' perception of NB. In case of two remaining 
exogenous constructs AOC19 and OCSE, ATOL was determined as a partial mediator for NB. This means that attitude as a mediator further intensifies the positive relationships among these constructs. While, for the endogenous construct INT, partial mediation of ATOL was noticed in case of all three exogenous constructs mentioned above. This also emphasized the enhancing role of ATOL as a mediator especially for the relationship between OCSE and INT, where the direct effect was found to be non-significant. This was also the case for CISE which indicated a partially significant direct effect on INT. These results supported the findings of Ferrer et al. (2020); Yasin et al. (2020); Alenezi et al. (2010) and Ndubisi (2004), who also studied significance of attitude as a mediator in online learning.

\section{Implications of the study}

\subsection{Theoretical implications}

This study contributes to the academic body of knowledge in the online learning field through the examination of NB as an outcome hitherto relatively unexplored in extant research in this domain. The study also examines the newly envisaged construct of AOC19 which is extremely relevant in the pandemic situation. The relevance of AOC19 as a "stimulus" under the SOR theory and its influence on the perception of net benefits by students in higher education is a concrete contribution by this study to the body of knowledge in this domain. While traditionally, the role of ATOL has been examined with respect to outcomes such as student satisfaction (Han et al., 2019; Malkawi et al., 2020; Wu et al., 2010) and intention to adopt online learning modes (Liu \& Pu, 2020), this study adds to the existing literature by examining the mediating role of ATOL between the exogenous constructs of AOC19, CISE, OCSE and NB which is a relatively less explored phenomenon in the knowledge field of online learning.

\subsection{Practical and social implications}

The sudden transition to online learning has posed significant challenges to faculty members. Enhanced student-faculty interaction through the online mode could be one of the alternatives of trying to improve the online communication skills of students which will in turn result in positive attitude and a greater perception of net benefits from the students' perspective. Additionally, faculty members would also need to engage in creating educational content more suited to the online mode of teaching, develop methods for grading and assessing students' performance on the online platforms, and also seek to improve their own capabilities with respect to effective delivery of online teaching. From educational institutions' perspective, it is imperative for them to engage in suitable instructional designs and aim at developing enhanced student experiences which translate into higher perception of benefits from online learning and also a favorable intentional disposition towards online 
learning. For the EdTech industry, development of easy to adopt tools which facilitate an enriched user experience for students and faculty members would go a long way in ensuring continued usage of online learning technologies.

\section{Conclusions, limitations and future research direction}

The ongoing COVID-19 pandemic has been instrumental in the transition of educational institutions towards online learning. This study attempted to assess the impact of the awareness of the ongoing pandemic on the how students would perceive the benefits that would accrue to them through the online learning mode and also attempted to understand the influence of this awareness on the intention of students towards the online learning mode. In addition, important variables such as the efficacy of students on two counts - computer and internet related as well as their online communication skills was also gauged in terms of their influence on perceived net benefits and intention towards online learning. The results have indicated AOC19 has indeed resulted in a perception of enhanced NB from the online learning mode as also a favorable INT of the students. However, over the last decade or so, computer \& internet capabilities of the youth in higher education have increased and therefore, being proficient in the use of the computer \& internet has resulted in students of higher education having greater expectation from the online learning mode. Online learning modes demand higher levels of communication skills and this is evident from the study where having good online communication skills drives a higher perception of net benefits as well as intention towards online learning. This study is one of the few that has focused on the perception of the net benefits derived from online learning as an outcome. The study also emphasizes the role of students' attitude as an important mediating variable with respect to the relationship between the exogenous and endogenous constructs.

This study has certain limitations. Firstly, it has been carried out during the pandemic situation wherein the online learning mode of education has been necessitated out of a fear of contracting COVID-19 as well as the need to maintain social distancing as stipulated by the governments and regulatory bodies. Therefore, the findings may not be generalizable in a post COVID-19 scenario. Secondly, this study is limited to students of higher education in India, nevertheless, it provides key insights into the factors relevant for the adoption of online learning technologies across the education spectrum. In addition, although the study has been carried out in India, it could open up avenues for future research across different countries. A critical research area would be the examination of how the online learning mode of education would be perceived in a post COVID-19 scenario.

Availability of data and material Yes, can be shared if required.

Code availability Not applicable. 


\section{Declarations}

Conflicts of interest/Competing interests Not applicable.

\section{References}

Abbas, Z., Umer, M., Odeh, M., McClatchey, R., Ali, A., \& Farooq, A. (2005). A semantic grid-based e-learning framework (SELF). In CCGrid 2005. IEEE International Symposium on Cluster Computing and the Grid, 2005. 1, pp. 11-18). IEEE.

Abdel-Wahab, A. G. (2008). Modeling Students' Intention to Adopt E-learning: A Case from Egypt. The Electronic Journal of Information Systems in Developing Countries, 34(1), 1-13.

Abdullah, F., Ward, R., \& Ahmed, E. (2016). Investigating the influence of the most commonly used external variables of TAM on students' Perceived Ease of Use (PEOU) and Perceived Usefulness (PU) of e-portfolios. Computers in Human Behavior, 63, 75-90.

Adarkwah, M. A. (2020). I'm not against online teaching, but what about us? ICT in Ghana post Covid19. Education and Information Technologies, 26, 1-21.

Ajzen, I., \& Fishbein, M. (1975). Intention and Behavior: An Introduction to Theory and Research. Addison-Wesley.

Ajzen, I., \& Fishbein, M. (1977). Attitude-behavior relations: A theoretical analysis and review of empirical research. Psychological Bulletin, 84(5), 888-918.

Ajzen, I. (1985). From intentions to actions: A theory of planned behavior. In Action control (pp. 11-39). Springer, Berlin, Heidelberg.

Albashrawi, M. A., Turner, L., \& Balasubramanian, S. (2020). Adoption of Mobile ERP in Educational Environment: Computer Self-Efficacy and System Security. International Journal of Enterprise Information Systems (IJEIS), 16(4), 184-200.

Alenezi, A. R., \& Karim, A. (2010). An empirical investigation into the role of enjoyment, computer anxiety, computer self-efficacy and internet experience in influencing the students' intention to use e-learning: A case study from Saudi Arabian governmental universities. Turkish Online Journal of Educational Technology-TOJET, 9(4), 22-34.

Al-Hattami, A. A. (2020). E-Assessment of Students Performance During the E-Teaching and Learning. International Journal of Advanced Science and Technology, 29(8s), 1537-1547.

Almaiah, M. A., Al-Khasawneh, A., \& Althunibat, A. (2020). Exploring the critical challenges and factors influencing the E-learning system usage during COVID-19 pandemic. Education and Information Technologies, 25, 5261-5280.

Almalki, O., Duan, Y., \& Frommholz, I. (2013). Developing a conceptual framework to evaluate e-government portals' success. In Proceedings of the 13th European Conference on e-Government. University of Insubria Varese, Italy 1, 19-26.

Alqahtani, A. Y., \& Rajkhan, A. A. (2020). E-learning critical success factors during the covid-19 pandemic: A comprehensive analysis of e-learning managerial perspectives. Education Sciences, 10(9), 216.

Alzahrani, A. I., Mahmud, I., Ramayah, T., Alfarraj, O., \& Alalwan, N. (2019). Modelling digital library success using the DeLone and McLean information system success model. Journal of Librarianship and Information Science, 51(2), 291-306.

Alzahrani, L., \& Seth, K. P. (2021). Factors influencing students' satisfaction with continuous use of learning management systems during the COVID-19 pandemic: An empirical study. Education and Information Technologies, 1-19.

Anaya, L. A. (2013). Realizing the benefits from enterprise information systems: A sociomaterial perspective. Procedia Technology, 9, 473-479.

Arora, R. (1982). Validation of an SOR model for situation, enduring, and response components of involvement. Journal of Marketing Research, 19(4), 505-516.

Bandura, A. (1977). Self-efficacy: Toward a unifying theory of behavioral change. Psychological Review, $84(2), 191$.

Bandura, A. (1982). The assessment and predictive generality of self-percepts of efficacy. Journal of Behavior Therapy and Experimental Psychiatry, 13(3), 195-199. 
Bartlett, M. S. (1950). Tests of significance in factor analysis. British Journal of Statistical Psychology, 3(2), 77-85.

Batra, R., \& Ray, M. L. (1986). Affective responses mediating acceptance of advertising. Journal of Consumer Research, 13(2), 234-249.

Bermejo, S. (2005). Cooperative electronic learning in virtual laboratories through forums. IEEE Transactions on Education, 48(1), 140-149.

Bhuasiri, W., Xaymoungkhoun, O., Zo, H., Rho, J. J., \& Ciganek, A. P. (2012). Critical success factors for e-learning in developing countries: A comparative analysis between ICT experts and faculty. Computers \& Education, 58(2), 843-855.

Buchanan, T., Sainter, P., \& Saunders, G. (2013). Factors affecting faculty use of learning technologies: Implications for models of technology adoption. Journal of Computing in Higher Education, 25(1), 1-11.

Caliskan, S., Suzek, S., \& Ozcan, D. (2017). Determining student satisfaction in distance education courses. Procedia Computer Science, 120, 529-538.

Casselman, M. A., \& Damhorst, M. L. (1991). Behavioral intentions and the apparel purchase decision: Testing the Fishbein Model. In ITAA Proceedings, 48, (p. 77).

Chang, C. L., \& Fang, M. (2020). E-Learning and online instructions of higher education during the 2019 novel coronavirus diseases (COVID-19) epidemic. In Journal of Physics: Conference Series, 1574 (1), (p. 012166). IOP Publishing.

Chen, Y. L., \& Huang, T. Z. (2012). Mechanism Research of OWOM Marketing Based on SOR and AISAS. Advanced Materials Research, 403, 3329-3333.

Chiu, Y. L., \& Tsai, C. C. (2014). The roles of social factor and internet self-efficacy in nurses' webbased continuing learning. Nurse Education Today, 34(3), 446-450.

Choi, D. H., Kim, J., \& Kim, S. H. (2007). ERP training with a web-based electronic learning system: The flow theory perspective. International Journal of Human-Computer Studies, 65(3), 223-243.

Chu, R. J. C. (2010). How family support and Internet self-efficacy influence the effects of e-learning among higher aged adults-Analyses of gender and age differences. Computers \& Education, 55(1), 255-264.

Coelho Junior, F. A., Botelho, E. D. A., Rego, M. C. B., Faiad, C., \& Ramos, W. M. (2019). Attitudes towards Online Learning: What Do Brazilian Students Think about? Turkish Online Journal of Distance Education, 20(4), 117-134.

Compeau, D. R., \& Higgins, C. A. (1995). Computer self-efficacy: Development of a measure and initial test. MIS Quarterly, 19(2), 189-211.

Csikszentmihalyi, M. (1997). Flow and Education. NAMTA Journal, 22(2), 2-35.

Dalvi-Esfahani, M., Wai Leong, L., Ibrahim, O., \& Nilashi, M. (2020). Explaining students' continuance intention to use Mobile web 2.0 learning and their perceived learning: An integrated approach. Journal of Educational Computing Research, 57(8), 1956-2005.

Davey, A. (2009). Statistical power analysis with missing data: A structural equation modeling approach. Routledge.

de Souza Rodrigues, M. A., Chimenti, P., \& Nogueira, A. R. R. (2021). An exploration of eLearning adoption in the educational ecosystem. Education and Information Technologies, 26(1), 585-615.

Delen, E., Liew, J., \& Willson, V. (2014). Effects of interactivity and instructional scaffolding on learning: Self-regulation in online video-based environments. Computers \& Education, 78, 312-320.

DeLone, W. H., \& McLean, E. R. (1992). Information systems success: The quest for the dependent variable. Information Systems Research, 3(1), 60-95.

DeLone, W. H., \& McLean, E. R. (2003). The DeLone and McLean model of information systems success: A ten-year update. Journal of Management Information Systems, 19(4), 9-30.

Eastin, M. S., \& LaRose, R. (2000). Internet self-efficacy and the psychology of the digital divide. Journal of computer-mediated communication, 6(1), JCMC611.

Elmorshidy, A. (2018). The impact of knowledge management systems on innovation. VINE Journal of Information and Knowledge Management Systems, 48(3), 388-403.

Ertz, M., Karakas, F., \& Sarigöllü, E. (2016). Exploring pro-environmental behaviors of consumers: An analysis of contextual factors, attitude, and behaviors. Journal of Business Research, 69(10), 3971-3980.

Evans, N. J., \& Bang, H. (2019). Extending expectancy violations theory to multiplayer online games: The structure and effects of expectations on attitude toward the advertising, attitude toward the brand, and purchase intent. Journal of Promotion Management, 25(4), 589-608. 
Farooq, A., Ndiege, J. R. A., \& Isoaho, J. (2019). Factors Affecting Security Behavior of Kenyan Students: An Integration of Protection Motivation Theory and Theory of Planned Behavior, 2019 IEEE AFRICON, 1-8.

Ferrer, J., Ringer, A., Saville, K., Parris, M. A., \& Kashi, K. (2020). Students' motivation and engagement in higher education: the importance of attitude to online learning. Higher Education, 1-22.

Fianu, E., Blewett, C., \& Ampong, G. O. (2020). Toward the development of a model of student usage of MOOCs. Education+ Training, 62(5), 521-541.

Field, A. P. (2005). Discovering statistics using SPSS (2nd ed.). Sage.

Fiore, A. M., \& Kim, J. (2007). An integrative framework capturing experiential and utilitarian shopping experience. International Journal of Retail \& Distribution Management., 35(6), 421-442.

Fornell, C., \& Larcker, D. F. (1981). Evaluating structural equation models with unobservable variables and measurement error. Journal of Marketing Research, 18(1), 39-50.

Gentry, L., \& Calantone, R. (2002). A comparison of three models to explain shop-bot use on the web. Psychology \& Marketing, 19(11), 945-956.

Govindarajan, V., \& Srivastava, A. (2020). What the shift to virtual learning could mean for the future of higher ed. Harvard Business Review, 31.

Guri-Rosenblit, S. (2005). 'Distance education' and 'e-learning': Not the same thing. Higher Education, 49(4), 467-493.

Hahne, A. K., Benndorf, R., Frey, P., \& Herzig, S. (2005). Attitude towards computer-based learning: Determinants as revealed by a controlled interventional study. Medical Education, 39(9), 935-943.

Hair, J. F., Black, W. C., Babin, B. J., Anderson, R. E., \& Tatham, R. (2006). Multivariate data analysis, Uppersaddle River, Pearson Prentice Hall

Han, H., Moon, H., \& Lee, H. (2019). Physical classroom environment affects students' satisfaction: Attitude and quality as mediators. Social Behavior and Personality: An International Journal, 47(5), $1-10$.

Hannafin, M. J. (1985). Empirical issues in the study of computer-assisted interactive video. ECTJ, 33(4), $235-247$.

Hartsell, T., \& Yuen, S. C. Y. (2006). Video streaming in online learning. AACE Journal, 14(1), 31-43.

Hassan, N. S., \& Seyal, A. (2015). Measuring success of higher education centralised administration information system: an e-government Initiative. In Proc. Eur. Conf. e-Government, ECEG (pp. 455-464).

Hassanzadeh, A., Kanaani, F., \& Elahi, S. (2012). A model for measuring e-learning systems success in universities. Expert Systems with Applications, 39(12), 10959-10966.

Hausman, A. V., \& Siekpe, J. S. (2009). The effect of web interface features on consumer online purchase intentions. Journal of Business Research, 62(1), 5-13.

Henseler, J., Ringle, C. M., \& Sarstedt, M. (2015). A new criterion for assessing discriminant validity in variance-based structural equation modeling. Journal of the Academy of Marketing Science, 43(1), $115-135$.

Hong, J. C., Hwang, M. Y., Tai, K. H., \& Lin, P. H. (2017). Intrinsic motivation of Chinese learning in predicting online learning self-efficacy and flow experience relevant to students' learning progress. Computer Assisted Language Learning, 30(6), 552-574.

Hung, M. L., Chou, C., Chen, C. H., \& Own, Z. Y. (2010). Learner readiness for online learning: Scale development and student perceptions. Computers \& Education, 55(3), 1080-1090.

Irani, Z., Ahmad, N., Amer, N. T., Qutaifan, F., \& Alhilali, A. (2013). Technology adoption model and a road map to successful implementation of ITIL. Journal of Enterprise Information Management, 26(5), 553-576.

Jashapara, A., \& Tai, W. C. (2006). Understanding the complexity of human characteristics on e-learning system: An integrated study of dynamic individual differences on user perceptions of ease of use. Knowledge Management Research \& Practice, 4(3), 227-239.

Jewer, J., Compeau, D., \& Besworth, M. (2017), Understanding IS adoption and success: Integration of IS success and technology adoption research, Proceedings of the Americas Conference on Information Systems, Boston, MA, USA, 10-12.

Ji, Z., Yang, Z., Liu, J., \& Yu, C. (2019). Investigating users' continued usage intentions of online learning applications. Information, 10(6), 198.

Jonassen, D., Davidson, M., Collins, M., Campbell, J., \& Haag, B. B. (1995). Constructivism and computermediated communication in distance education. American Journal of Distance Education, 9(2), 7-26.

Kaur, S., Lal, A. K., \& Bedi, S. S. (2017). Do vendor cues influence purchase intention of online shoppers? An empirical study using SOR framework. Journal of Internet Commerce, 16(4), 343-363. 
Kim, J. H., \& Lennon, S. (2012). Music and amount of information: Do they matter in an online apparel setting? The International Review of Retail, Distribution and Consumer Research, 22(1), 55-82.

Kim, B., \& Park, M. J. (2018). Effect of personal factors to use ICTs on e-learning adoption: Comparison between learner and instructor in developing countries. Information Technology for Development, 24(4), 706-732.

Koh, C. E., Prybutok, V. R., Ryan, S. D., \& Wu, Y. (2010). A model for mandatory use of software technologies: An integrative approach by applying multiple levels of abstraction of informing science. Informing Science, 13, 177-203.

Koohang, A., \& Harman, K. (2005). Open source: A metaphor for e-learning. Informing Science, 8, $75-86$.

Korkmaz, Ö. (2012). A validity and reliability study of the Online Cooperative Learning Attitude Scale (OCLAS). Computers \& Education, 59(4), 1162-1169.

Krishnamurthy, S. (2020). The future of business education: A commentary in the shadow of the Covid19 pandemic. Journal of Business Research, 117, 1-5.

Kurkalova, L. A., \& Carter, L. (2017). Sustainable production: Using simulation modeling to identify the benefits of green information systems. Decision Support Systems, 96, 83-91.

Lam, L. W. (2012). Impact of competitiveness on salespeople's commitment and performance. Journal of Business Research, 65(9), 1328-1334.

Lee, S., Ha, S., \& Widdows, R. (2011). Consumer responses to high-technology products: Product attributes, cognition, and emotions. Journal of Business Research, 64(11), 1195-1200.

Liao, C., Lin, H. N., Luo, M. M., \& Chea, S. (2017). Factors influencing online shoppers' repurchase intentions: The roles of satisfaction and regret. Information \& Management, 54(5), 651-668.

Lim, S., \& Tai, K. (2014). Family incivility and job performance: A moderated mediation model of psychological distress and core self-evaluation. Journal of Applied Psychology, 99(2), 351.

Lim, K., Kang, M., \& Park, S. Y. (2016). Structural relationships of environments, individuals, and learning outcomes in Korean online university settings. International Review of Research in Open and Distributed Learning, 17(4), 315-330.

Lin, P. C., Lu, H. K., \& Liu, S. C. (2013). Towards an education behavioral intention model for e-learning systems: An extension of UTAUT. Journal of Theoretical \& Applied Information Technology, 47(3), 1120-1127.

Liu, I. F., Chen, M. C., Sun, Y. S., Wible, D., \& Kuo, C. H. (2010). Extending the TAM model to explore the factors that affect intention to use an online learning community. Computers \& Education, 54(2), 600-610.

Liu, N., \& Pu, Q. (2020). Factors influencing learners' continuance intention toward one-to-one online learning. Interactive Learning Environments, 1-22.

Liu, J. L., \& Zhao, G. D. (2018). The Measurement and Determinants of Student Satisfaction of Education Informatization in Chinese Universities, 2018 International Symposium on Educational Technology (ISET), (pp. 183-187).

Lwoga, E. T. (2013). Measuring the success of library 2.0 technologies in the African context. CampusWide Information Systems, 30(4), 288-307.

Malkawi, E., Bawaneh, A. K., \& Bawa'aneh, M. S. (2020). Campus Off, Education On: UAEU Students' Satisfaction and Attitudes Towards E-Learning and Virtual Classes During COVID-19 Pandemic. Contemporary Educational Technology, 13(1), ep283.

Markova, G., \& Jones, F. (2011). Attitude formation of benefits satisfaction: Knowledge and fit of benefits. Internationl Journal of Business Research and Management, 2(1), 45-52.

Marnewick, C. (2016). Benefits of information system projects: The tale of two countries. International Journal of Project Management, 34(4), 748-760.

Mathew, N. G., Sreehari, P., \& Al-Rubaat, A. M. (2019). Challenges and implications of virtual e-learning platform in EFL context: Perceptions of teachers. International Journal of English Language Teaching, 7(2), 100-116.

McVay, M. (2000). How to be a Successful Distance Learning Student: Learning on the Internet. NY, Prentice-Hall.

Means, B., Toyama, Y., Murphy, R., \& Baki, M. (2013). The effectiveness of online and blended learning: A meta-analysis of the empirical literature. Teachers College Record, 115(3), 1-47.

Mehrabian, A., \& Russell, J. A. (1974). An approach to environmental psychology. the MIT Press.

Merkle, L. A., Layne, C. S., Bloomberg, J. J., \& Zhang, J. J. (1998). Using factor analysis to identify neuromuscular synergies during treadmill walking. Journal of Neuroscience Methods, 82(2), 207-214. 
Ministry of Human Resource Development. (2019). All India Survey on Higher Education, available at: http://aishe.nic.in/aishe/viewDocument.action?documentId=262 (accessed 20 October 2020)

Mo, C. Y., Hsieh, T. H., Lin, C. L., Jin, Y. Q., \& Su, Y. S. (2021). Exploring the Critical Factors, the Online Learning Continuance Usage during COVID-19 Pandemic. Sustainability, 13(10), 5471.

Moon, M. A., Khalid, M. J., Awan, H. M., Attiq, S., Rasool, H., \& Kiran, M. (2017). Consumer's perceptions of website's utilitarian and hedonic attributes and online purchase intentions: A cognitiveaffective attitude approach. Spanish Journal of Marketing-ESIC, 21(2), 73-88.

Moon, M. A., Javaid, B., Kiran, M., Awan, H. M., \& Farooq, A. (2018). Consumer perceptions of counterfeit clothing and apparel products attributes. Marketing Intelligence \& Planning, 36(7), 794-808.

Mosquera, L. H. (2017). Impact of implementing a virtual learning environment (vle) in the efl classroom. Íkala: Revista de Lenguaje y Cultura, 22(3), 479-498

Mpungose, C. B. (2020). Emergent transition from face-to-face to online learning in a South African University in the context of the Coronavirus pandemic. Humanities and Social Sciences Communications, 7(1), 1-9.

Mukhtar, K., Javed, K., Arooj, M., \& Sethi, A. (2020). Advantages, Limitations and Recommendations for online learning during COVID-19 pandemic era. Pakistan Journal of Medical Sciences, 36, $27-31$.

Munir, F., Saeed, I., Shuja, A., \& Aslam, F. (2021). Students Fear of COVID-19, Psychological Motivation, Cognitive Problem-Solving Skills and Social Presence in Online Learning. International Journal of Education and Practice, 9(1), 141-154.

Ndubisi, N. O. (2004). Factors influencing e-learning adoption intention: Examining the determinant structure of the decomposed theory of planned behavior constructs. Proceedings of the 27th Annual Conference of HERDSA, (pp. 252-262).

Nunnally, J. C. (1978). Psychometric Theory. NY, McGrawHill.

Paloff, R., \& Pratt, K. (1999). Promoting collaborative learning, Building learning communities in cyberspace, San Francisco, Jossey-Bass.

Park, C., \& Kim, D. G. (2020). Perception of Instructor Presence and Its Effects on Learning Experience in Online Classes. Journal of Information Technology Education: Research, 19, 475-488.

Preacher, K. J., \& Hayes, A. F. (2004). SPSS and SAS procedures for estimating indirect effects in simple mediation models. Behavior Research Methods, Instruments, \& Computers, 36(4), 717-731.

Preacher, K. J., \& Hayes, A. F. (2008). Asymptotic and resampling strategies for assessing and comparing indirect effects in multiple mediator models. Behavior Research Methods, 40(3), 879-891.

Rajabalee, Y. B., \& Santally, M. I. (2020). Learner satisfaction, engagement and performances in an online module: Implications for institutional e-learning policy. Education and Information Technologies, 26, 2623-2656.

Richardson, J., \& Swan, K. (2003). Examining social presence in online courses in relation to students' perceived learning and satisfaction. Journal of Asynchronous Learning Network, 7(1), 68-88.

Romero, J., Ruiz-Equihua, D., Loureiro, S. M. C., \& Casaló, L. V. (2021). Smart Speaker Recommendations: Impact of Gender Congruence and Amount of Information on Users' Engagement and Choice. Frontiers in Psychology, 12, 1037.

Roper, A. R. (2007). How students develop online learning skills. Educause Quarterly, 30(1), 62.

Safiih, L. M., \& Azreen, N. (2016). Confirmatory factor analysis approach: A case study of mathematics students' achievement in timss. Malaysian Journal of Mathematical Sciences, 10, 41-51.

Salam, M., \& Farooq, M. S. (2020). Does sociability quality of web-based collaborative learning information system influence students' satisfaction and system usage? International Journal of Educational Technology in Higher Education, 17, 1-39.

Shaft, T. M., Sharfman, M. P., \& Wu, W. W. (2004). Reliability assessment of the attitude towards computers instrument (ATCI). Computers in Human Behavior, 20(5), 661-689.

Shen, D., Cho, M. H., Tsai, C. L., \& Marra, R. (2013). Unpacking online learning experiences: Online learning self-efficacy and learning satisfaction. The Internet and Higher Education, 19, 10-17.

Sidik, D., \& Syafar, F. (2020). Exploring the factors influencing student's intention to use mobile learning in Indonesia higher education. Education and Information Technologies, 25(6), 4781-4796.

Sreehari, P. (2020). Online learning during the covid-19 lockdown: Learners' perceptions. Journal of Critical Reviews, 7(19), 300-307.

Stevens, J. P. (1996). Applied multivariate statistics for the social sciences. Lawrence Erlbaum.

Sumuer, E. (2018). Factors related to college students' self-directed learning with technology. Australasian Journal of Educational Technology, 34(4), 29-43. 
Suparno, C. (2020). Online purchase intention of halal cosmetics: SOR framework application. Journal of Islamic Marketing.

Tabachnick, B. G., Fidell, L. S., \& Ullman, J. B. (2007). Using multivariate statistics 5, 481-498. MA, Pearson.

Taleb, N. N. (2007). The black swan: The impact of the highly improbable (Vol. 2). London, Random house.

Tseng, F. C., \& Kuo, F. Y. (2010). The way we share and learn: An exploratory study of the self-regulatory mechanisms in the professional online learning community. Computers in Human Behavior, 26(5), 1043-1053.

Udo, G. J., Bagchi, K. K., \& Kirs, P. J. (2010). An assessment of customers'e-service quality perception, satisfaction and intention. International Journal of Information Management, 30(6), 481-492.

Vergura, D. T., Zerbini, C., \& Luceri, B. (2020). Consumers' attitude and purchase intention towards organic personal care products. An application of the SOR model. Sinergie Italian Journal of Management, 38(1), 121-137.

Volery, T., \& Lord, D. (2000). Critical success factors in online education. International Journal of Educational Management, 14(5), 216-223.

Wahid, F. (2007). Using the technology adoption model to analyze internet adoption and use among men and women in Indonesia. The Electronic Journal of Information Systems in Developing Countries, $32(1), 1-8$.

Wenzel, A., \& Gotfredsen, E. (1997). Students' attitudes towards and use of computer-assisted learning in oral radiology over a 10-year period. Dentomaxillofacial Radiology, 26(2), 132-136.

Wu, J. H., Tennyson, R. D., \& Hsia, T. L. (2010). A study of student satisfaction in a blended e-learning system environment. Computers \& Education, 55(1), 155-164.

Xinli, H. (2015). Effectiveness of information technology in reducing corruption in China. The Electronic Library, 33(1), 52-64.

Xu, N., \& Wang, H. (2017). Research on Impact Factors of User's Continuance Intention in Online Education Platform. In 2017 International Conference on Industrial Informatics-Computing Technology, Intelligent Technology, Industrial Information Integration (ICIICII) (pp. 95-99). IEEE.

Yasin, N. M., Ongb, M. H. A., \& Abd Azizc, N. N. (2020). Attitude as Mediator of Technical Usage Self-Efficacy, Online Communication Self-Efficacy, Technology Access and Online Media on the Blended Learning Readiness. 29(6), 713 - 724

Yokoyama, S. (2019). Academic self-efficacy and academic performance in online learning: A mini review. Frontiers in Psychology, 9, 2794.

Yusuf, A. S., CheHussin, A. R., \& Busalim, A. H. (2018). Influence of e-WOM engagement on consumer purchase intention in social commerce. Journal of Services Marketing, 32(4), 493-504.

Zahid, H., \& Haji Din, B. (2019). Determinants of intention to adopt e-government services in Pakistan: An imperative for sustainable development. Resources, 8(3), 128.

Zhai, X., Wang, M., \& Ghani, U. (2020). The SOR (stimulus-organism-response) paradigm in online learning: An empirical study of students' knowledge hiding perceptions. Interactive Learning Environments, 28(5), 586-601.

Zhang, L., \& Thompson, R. G. (2019). Understanding the benefits and limitations of occupancy information systems for couriers. Transportation Research Part c: Emerging Technologies, 105, 520-535.

Zhou, M. (2016). Chinese university students' acceptance of MOOCs: A self-determination perspective. Computers \& Education, 92, 194-203.

Publisher's note Springer Nature remains neutral with regard to jurisdictional claims in published maps and institutional affiliations.

\section{Authors and Affiliations}

\section{Krunal K. Punjani ${ }^{1}$ (D) Kala Mahadevan ${ }^{1}$}

Kala Mahadevan

kalamahadevan11@gmail.com

1 Dr. V. N. Bedekar Institute of Management Studies, Maharashtra, Thane, India 